\title{
PERANCANGAN SISTEM INFORMASI ADMISI PROGRAM PASCASARJANA UNIVERSITAS SAM RATULANGI
}

\author{
Shalahudin A.P. Djafar ${ }^{1)}$, Stanley D.S. Karouw ${ }^{2)}$, Meicsy E.I. Najoan ${ }^{3)}$ \\ ${ }^{1,2,3}$ Program Studi Teknik Informatika, Fakultas Teknik, Universitas Sam Ratulangi \\ Jl. Kampus UNSRAT Bahu, Manado, 95115 \\ Telp : (0431) 852959, Fax : (0431) 823705 \\ E-mail : shalahudin.djafar@yahoo.com ${ }^{1)}$, stanleydsk@gmail.com ${ }^{2)}$, meicsynajoan@gmail.com ${ }^{3)}$
}

\begin{abstract}
Abstrak
Kegiatan pengelolaan akademik di Program Pascasarjana Universitas Sam Ratulangi (Unsrat) Manado khususnya dalam proses pendaftaran mahasiswa baru masih menggunakan model sistem manual yaitu masih menggunakan formulir pendaftaran tertulis. Proses yang sering kali tidak efisien dan memakan waktu yang lama, serta data yang mudah hilang atau tercecer merupakan kelemahan dari model sistem ini. Konsep rekayasa perangkat lunak serta analisa dan perancangan sistem menggunakan metode pengembangan perangkat lunak Rapid Application Development (RAD) dan Web Engineering (WebE) dapat diterapkan untuk mengatasi masalah tersebut. Proses analisa dan perancangan sistem dengan kombinasi dua metode tersebut dapat menghasilkan sebuah Sistem Informasi Admisi berbasis web yang sudah dapat digunakan dan memiliki dokumentasi yang lengkap.
\end{abstract}

Kata kunci: Sistem Informasi Admisi, Program Pascasarjana Unsrat, RAD, WebE

\section{PENDAHULUAN}

\subsection{Latar Belakang}

Sutabri[1] mendefinisikan sistem informasi adalah suatu sistem didalam suatu organisasi yang mempertemukan kebutuhan pengolahan transaksi harian yang mendukung fungsi operasi organisasi yang bersifat manajerial dengan kegiatan strategi dari suatu organisasi untuk dapat menyediakan kepada pihak luar tertentu dengan laporan-laporan yang diperlukan.

Kegiatan akademik Program Pascasarjana Unsrat khususnya dalam proses pendaftaran mahasiswa baru masih menggunakan model sistem yang lama yaitu masih menggunakan formulir tertulis dan belum menggunakan atau mengembangkan sebuah teknologi di bidang Teknologi Informasi (TI) seperti misalnya sistem informasi pendaftaran berbasis web.

Masalah pendaftaran mahasiswa baru ini seharusnya sudah bisa teratasi dengan teknologi yang ada sekarang. Sudah banyak perguruan tinggi bahkan sekolah yang sudah menggunakan sistem informasi berbasis web dalam meyelesaikan masalah pendaftaran ini. Selain itu, dengan adanya teknologi internet yang tersedia di mana saja membuat akses ke sistem informasi berbasis web menjadi semakin mudah.

Hal ini yang menyebabkan penulis merasa perlu merancang suatu teknologi untuk mengefisiensi proses penerimaan mahasiswa baru ini ke dalam sebuah sistem informasi admisi berbasis web, guna mempermudah proses pendaftaran mahasiswa baru di Program Pascasarjana Unsrat Manado.

\subsection{Tujuan}

Perancangan Sistem Informasi Admisi Program Pascasarjana Unsrat ini bertujuan untuk: (1) Menerapkan konsep rekayasa perangkat lunak serta analisa dan perancangan sistem dalam menyelesaikan masalah pendaftaran mahasiswa baru di Program Pascasarjana Unsrat; (2) Menerapkan metode pengembangan perangkat lunak cepat RAD dan metode pengembangan aplikasi web WebE pada proses sistem informasi berbasis web; (3) Menghasilkan sebuah produk aplikasi yang dapat digunakan.

\section{LANDASAN TEORI}

\subsection{Sistem Informasi}

Sutabri[1] mengemukakan sistem informasi terdiri dari komponen-komponen yang disebut dengan istilah blok bangunan (building block), yang terdiri dari blok masukan, blok model, blok keluaran, blok teknologi, blok basis data dan blok kendali. Sebagai suatu sistem, keenam blok tersebut saling berinteraksi satu dengan yang lain 
membentuk satu kesatuan untuk mencapai sasaran. Skema dari suatu sistem informasi dapat dilihat pada gambar 1 .

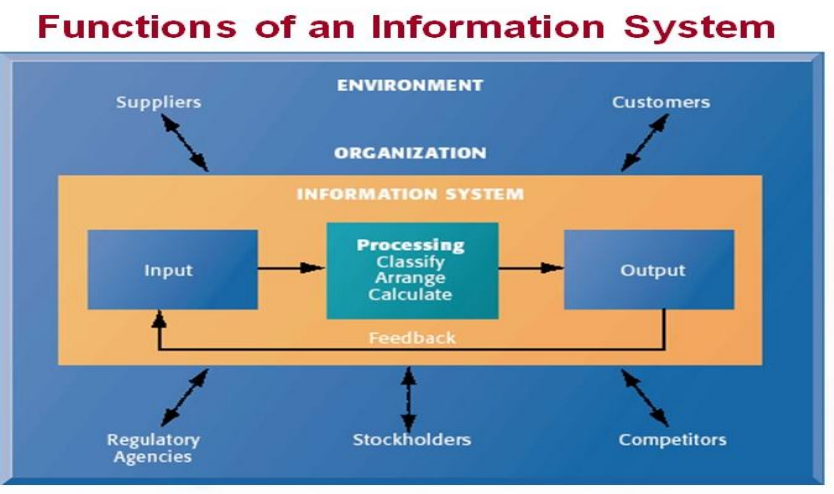

Gambar 1 Skema Sistem Informasi

\subsection{Analisa dan Perancangan Sistem}

Karouw[2] mengemukakan bahwa analisa sistem bertujuan untuk mendapatkan pemahaman secara keseluruhan tentang sistem yang akan dikembangkan, berdasarkan masukan dari user atau pihak lain yang berkepentingan. Namun tujuan utama dari analisa sistem adalah memodelkan sistem yang nyata dengan penekanan pada apa yang harus dilakukan, bukan pada bagaimana melakukannya.

\subsection{Teknologi Aplikasi Web}

Janner[3] mendefinisikan aplikasi web sebagai suatu aplikasi yang sejak awal dirancang untuk dieksekusi di dalam lingkungan berbasis web. Definisi ini mengungkapkan aspek-aspek penting dari aplikasi, yaitu:

1) Suatu aplikasi web dirancang agar dapat berjalan di dalam lingkungan berbasis web. Artinya, aspek-aspek hipermedia dalam kaitannya dengan hiperteks dan multimedia di dalam kombinasi dengan logika aplikasi tradisional harus diperhitungkan di seluruh siklus hidup aplikasi, yang membuatnya berbeda dengan aplikasi konvensional.

2) Aplikasi web adalah suatu aplikasi yang tidak hanya berupa sekumpulan halaman-halaman web.

3) Secara khusus, aplikasi web menguatkan notasi sesi yang membedakannya dari paradigma web permintaanrespons (request-response) yang biasa. Dalam konteks ini, web service secara dinamis akan menghasilkan halaman yang tidak mungkin dipertimbangkan aplikasi web.

Contoh bagan suatu aplikasi web dapat dilihat pada gambar 2.

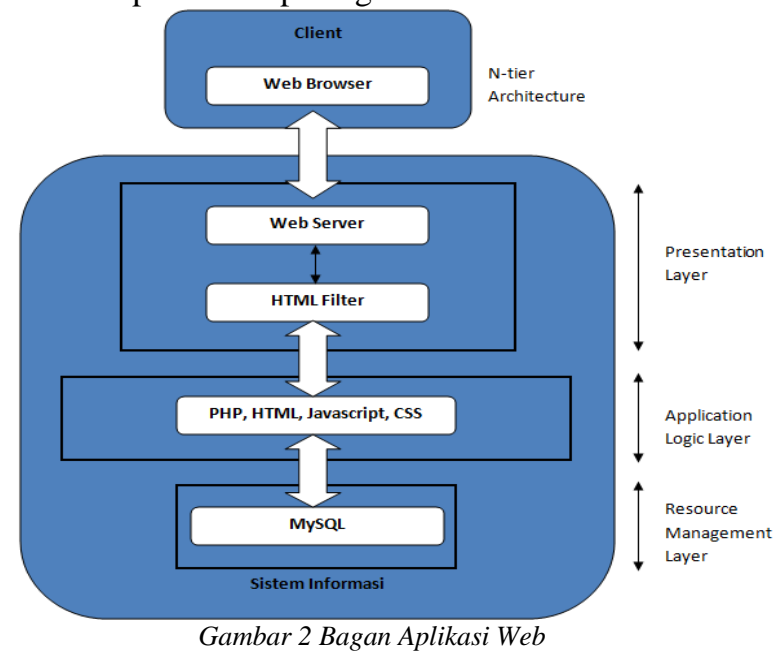

\subsection{Rapid Application Development (RAD)}

RAD atau pengembangan aplikasi cepat, dikemukakan oleh Kendall[4] adalah pendekatan berorientasi objek untuk pengembangan sistem yang meliputi metode pengembangan serta perangkat lunak. Kendal dan Kendall[5] melihat RAD sebagai metodologi pengembangan sistem yang berusaha untuk mengatasi perubahan persyaratan kebutuhan user dan merekomendasikan RAD untuk mengembangkan aplikasi berbasis web. Menurut Pressman[6], RAD merupakan model proses perangkat lunak yang menekankan pada daur pengembangan hidup yang singkat. Sedangkan menurut Schach[7], Suatu model rapid prototype, merupakan working model dimana sebagian fungsional aplikasi sudah berjalan. Tahapan RAD terdiri dari 3 fase yaitu: (1) Requirements Planning; (2) RAD Deign Workshop; (3) Implementation. 


\subsection{Web Engineering (WebE)}

Boch dan Grady[8] mengemukakan bahwa Web Engineering (rekayasa web) adalah suatu proses yang digunakan untuk menciptakan kualitas web menjadi lebih tinggi. Tujuannya adalah untuk meminimalisasi resiko dan meningkatkan kualitas sistem berbasis web. Aktifitas-aktifitas yang dilakukan dalam metode WebE ini antara lain: (1) Communication; (2) Planning; (3) Modelling; (4) Construction; (5) Deployment.

\section{METODOLOGI PEMECAHAN MASALAH}

\subsection{Prosedur}

Prosedur pemecahan masalah yang digunakan diadaptasi dari langkah-langkah metode penelitian eksperimen pada tulisan Romi[9] tentang research metodology dan struktur penulisan tesis.

\subsection{Metode Pengembangan Perangkat Lunak}

Metode pengembangan perangkat lunak yang digunakan dalam mengembangkan Sistem Informasi Admisi Program Pascasarjana Unsrat ini menggunakan kombinasi dua metode yaitu metode RAD dan WebE. Kombinasi kedua metode ini menghasilkan langkah-langkah perancangan sistem yang lebih komprehensif. Gambar 3 menjelaskan skema dari prosedur pemecahan masalah dan metode pengembangan perangkat lunak yang digunakan.

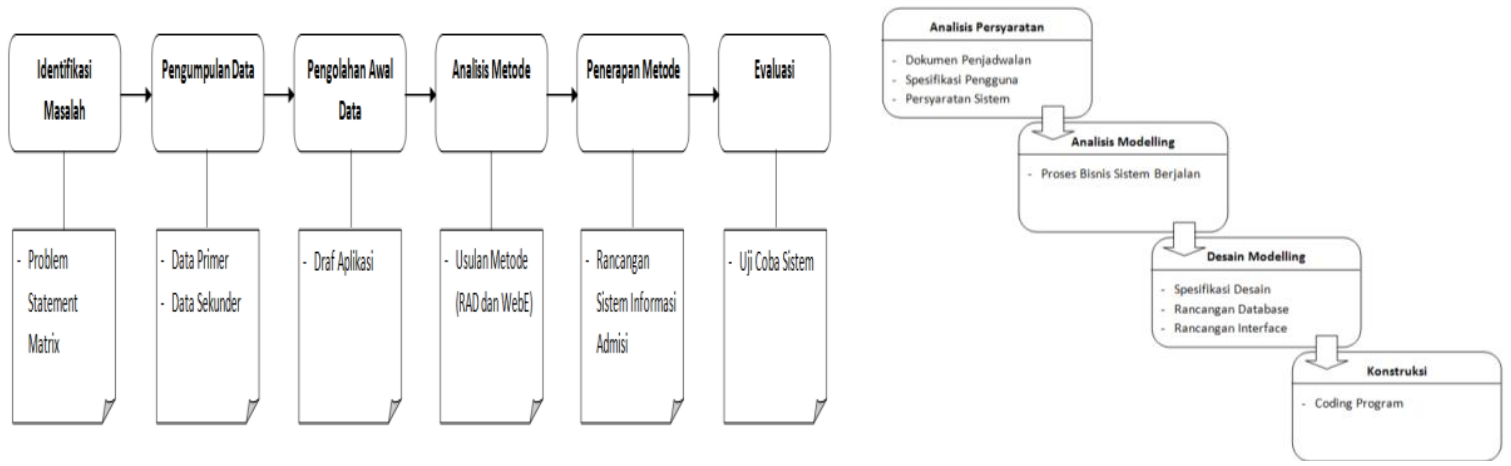

Gambar 3 Skema Prosedur dan Metode yang Digunakan

\section{PEMBAHASAN}

Prosedur yang digunakan dalam perancangan Sistem Informasi Admisi Program Pascasarjana Unsrat ini langkah-langkahnya sebagai berikut:

1) Identifikasi Masalah

2) Pengumpulan Data

3) Pengolahan Awal Data

4) Analisis Metode

5) Penerapan Metode

6) Evaluasi

\subsection{Identifikasi Masalah}

Tahap identifikasi masalah bertujuan untuk melakukan identifikasi mengenai masalah utama yang ada. Hasil dari tahap identifikasi masalah ini berupa tabel problem statement matrix (lihat tabel 1). Tabel problem statement matrix memuat permasalahan utama yang ada, dampak yang disebabkan oleh permasalahan tersebut, dan solusi yang diusulkan oleh penulis untuk memecahkan masalah tersebut.

Tabel 1 Problem Statement Matrix

\begin{tabular}{|l|l|}
\hline The problem of & $\begin{array}{l}\text { Proses bisnis yang masih menggunakan sistem manual yang tidak efisien } \\
\text { dan memiliki banyak kekurangan } \\
\text { Data mudah hilang atau tercecer } \\
\text { Proses pendaftaran atau registrasi }\end{array}$ \\
\hline $\begin{array}{l}\text { Affects } \\
\text { which is }\end{array}$ & Proses registrasi memakan waktu yang lama \\
\hline $\begin{array}{l}\text { A successful } \\
\text { solution would be }\end{array}$ & $\begin{array}{l}\text { Merancang sebuah Sistem Informasi Admisi berbasis web dan memiliki } \\
\text { database sendiri sebagai tempat penyimpanan data sehingga dapat } \\
\text { mempermudah proses pendaftaran mahasiswa baru di program Pascasarjana } \\
\text { Unsrat Manado }\end{array}$ \\
\hline
\end{tabular}




\subsection{Pengumpulan Data}

Tahap pengumpulan data dilakukan dengan langkah wawancara, observasi lapangan, dan studi pustaka. Hasil dari tahap ini berupa data-data yang terbagi atas data primer dan data sekunder. Data-data primer yang didapatkan salah satunya adalah formulir pendaftaran fisik Program Pascasarjana Unsrat (lihat gambar 4). Sedangkan data sekunder yang didapatkan berupa kontribusi penelitian yang tidak ditampilkan dalam paper ini.
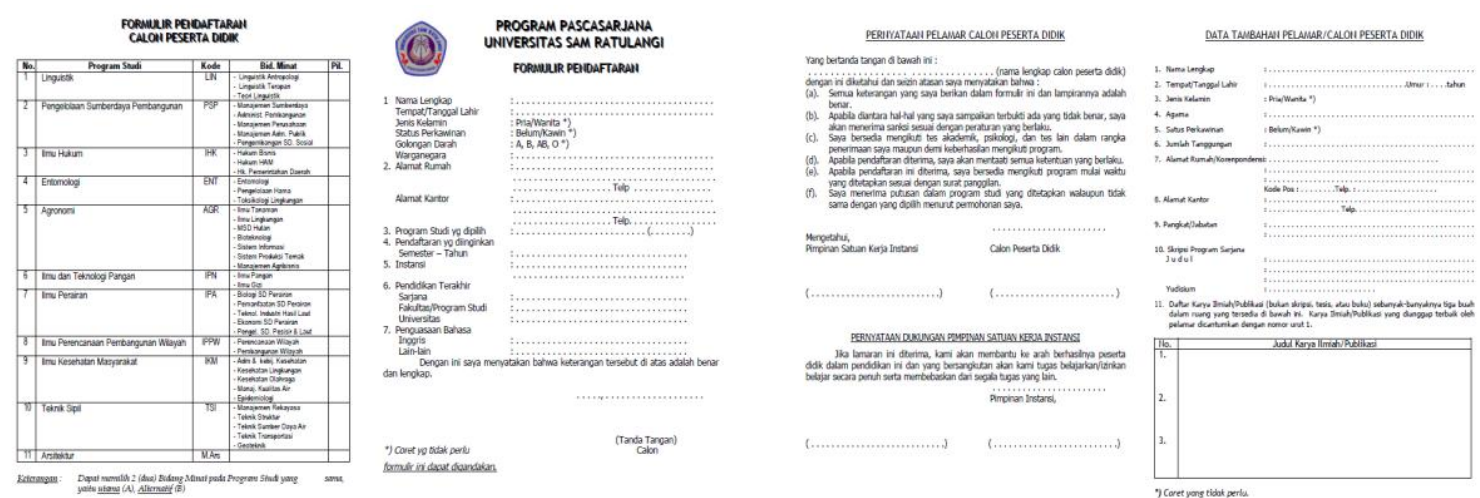

Gambar 4 Formulir Pendaftaran Fisik Program Pascasarjana Unsrat

\subsection{Pengolahan Awal Data}

Dari data-data yang diperoleh yaitu data formulir pendaftaran fisik Program Pascasarjana Unsrat, dilakukan pengolahan awal data sehingga menghasilkan dokumen yaitu draf aplikasi berupa konsep formulir pendaftaran online yang berisi data-data atribut yang akan digunakan dalam membangun sistem.

\subsection{Analisis Metode}

Tahap analisis metode dilakukan untuk menganalisa jenis sistem yang akan dibangun serta menganalisa metode pengembangan perangkat lunak yang cocok untuk membangun sistem. Hasil dari tahap ini berupa usulan metode yang akan digunakan, yaitu kombinasi metode RAD dan WebE yang menghasilkan langkah-langkah pemecahan masalah yang lebih komprehensif.

\subsection{Penerapan Metode}

Setelah memperoleh usulan metode yang akan digunakan yaitu kombinasi metode RAD dan WebE, maka dilakukan tahap penerapan metode dimana metode tersebut diimplementasikan dalam masalah perancangan Sistem Informasi Admisi Program Pascasarjana Unsrat. Langkah-langkah yang dilakukan dalam metode tersebut adalah sebagai berikut:

1) Analisis Persyaratan

Langkah analisis persyaratan bertujuan untuk melakukan perencanaan dan penjadwalan perancangan sistem serta mengidentifikasi kebutuhan pengguna dan spesifikasi sistem melalui hasil observasi dan pengumpulan data yang dilakukan terhadap stakeholder, sehingga sistem yang akan dibuat akan sesuai dengan yang dibutuhkan oleh pengguna. Hasil dari langkah ini diantaranya berupa tabel spesifikasi pengguna (lihat tabel 2) yang menjelaskan spesifikasi pengguna dari sistem yang akan dibangun beserta peran dan tanggung jawab masingmasing pengguna.

Tabel 2 Spesifikasi Pengguna

\begin{tabular}{|l|l|l|}
\hline \multicolumn{1}{|c|}{ Pengguna } & \multicolumn{1}{c|}{ Peran } & \multicolumn{1}{c|}{ Tanggung Jawab } \\
\hline Admin PTI & Admin & $\begin{array}{l}\text { Aktor yang menggunakan Sistem Informasi Admisi Program } \\
\text { Pascasarjana Unsrat untuk mengelola data calon mahasiswa } \\
\text { yang telah mendaftar }\end{array}$ \\
\hline Admin Bank & Admin & $\begin{array}{l}\text { Aktor yang menggunakan Sistem Informasi Admisi Program } \\
\text { Pascasarjana Unsrat untuk menambahkan data baru calon } \\
\text { mahasiswa yang akan melakukan proses pendaftaran }\end{array}$ \\
\hline $\begin{array}{l}\text { Calon } \\
\text { Mahasiswa }\end{array}$ & User & $\begin{array}{l}\text { Aktor yang menggunakan Sistem Informasi Admisi Program } \\
\text { Pascasarjana Unsrat untuk melakukan proses pendaftaran }\end{array}$ \\
\hline
\end{tabular}

\section{2) Analisis Modelling}

Langkah analisis modelling bertujuan untuk menganalisis sistem yang berjalan dari semua kegiatan yang terjadi pada sistem. Hasil dari langkah ini berupa proses bisnis dari sistem yang berjalan (lihat gambar 5). 


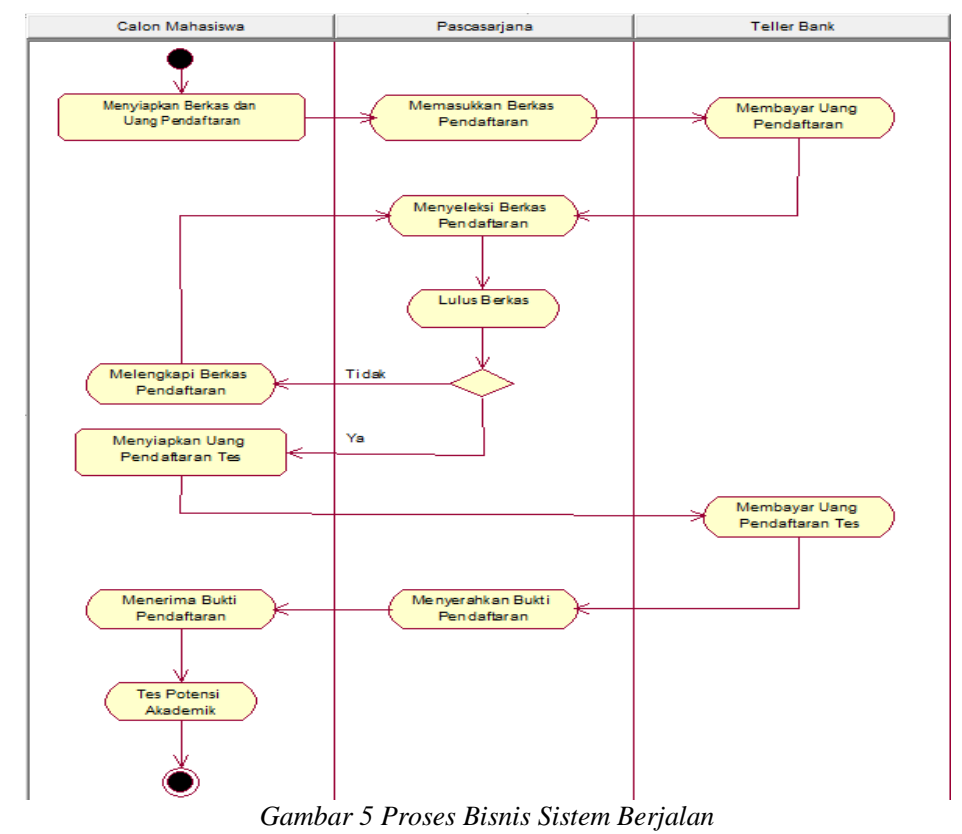

\section{3) Desain Modelling}

Langkah desain modelling bertujuan untuk melakukan perancangan sistem melalui hasil analisis yang telah dilakukan sebelumnya. Pada langkah ini terjadi iterasi perancangan proses bisnis sistem sehingga menghasilkan proses bisnis yang diinginkan untuk membangun sistem. Hasil dari langkah ini berupa spesifikasi desain yang antara lain berupa diagram-diagram UML seperti use case diagram dan activity diagram (lihat gambar 6).

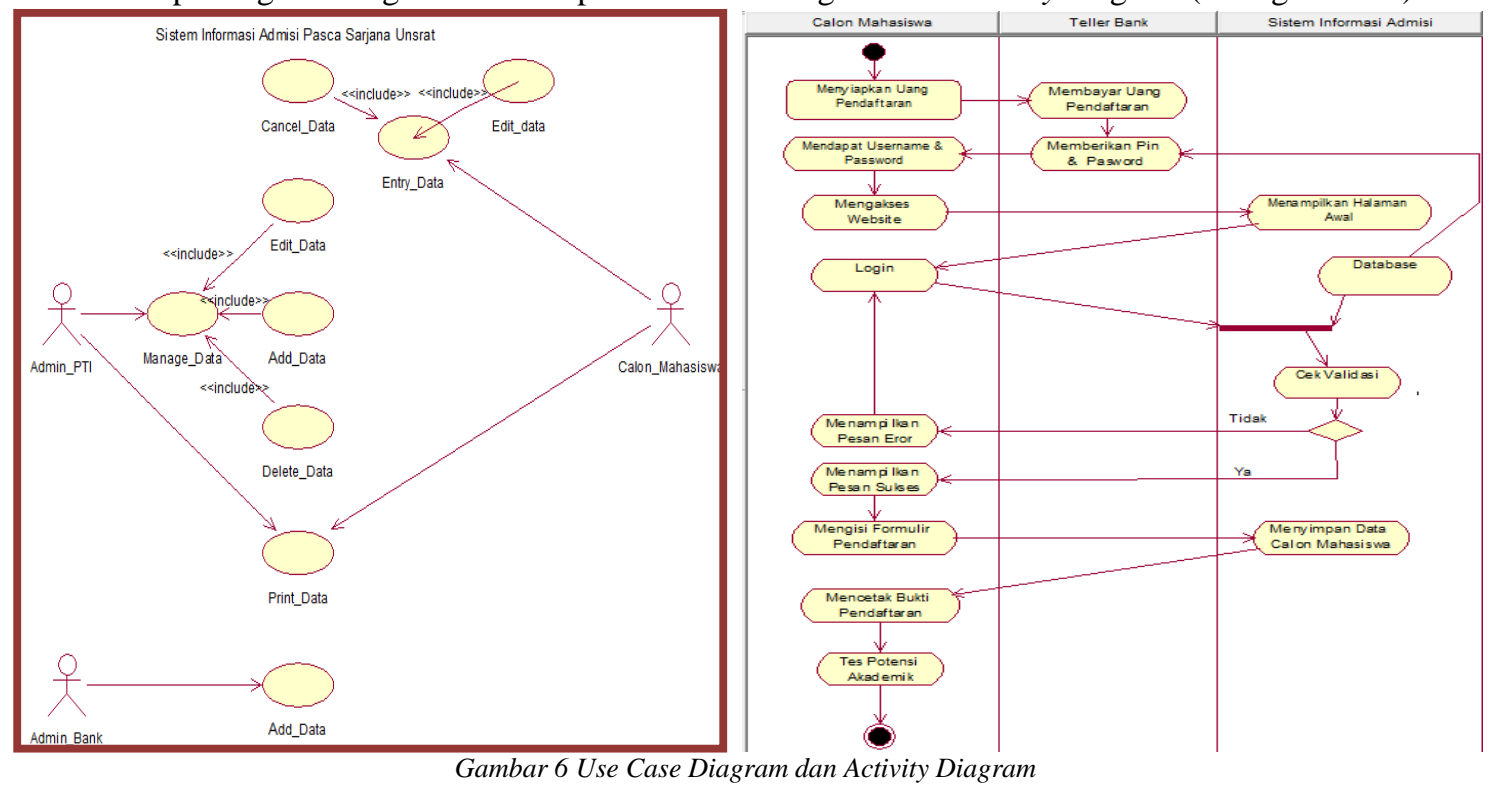

\section{4) Konstruksi}

Langkah konstruksi bertujuan untuk membangun sistem berdasarkan hasil desain modelling yang telah didapatkan. Berdasarkan hasil desain modelling, dilakukan konstruksi berupa coding atau kodifikasi program. Kodifikasi merupakan proses penulisan source code atau kode-kode sumber yang akan membangun sistem dari segi interface sistem dan logika atau proses dari sistem itu sendiri. Kode-kode sumber yang digunakan dalam tahap kodifikasi ini antara lain kode sumber HTML dan CSS sebagai perancangan antarmuka atau interface sistem, serta kode sumber PHP sebagai bahasa pemrograman yang membentuk logika atau proses dari sistem. Hasil dari langkah konstruksi ini berupa kode sumber atau source code program. Penggalan kode sumber program dan interface sistem hasil kodifikasi program dapat dilihat pada gambar 7. 


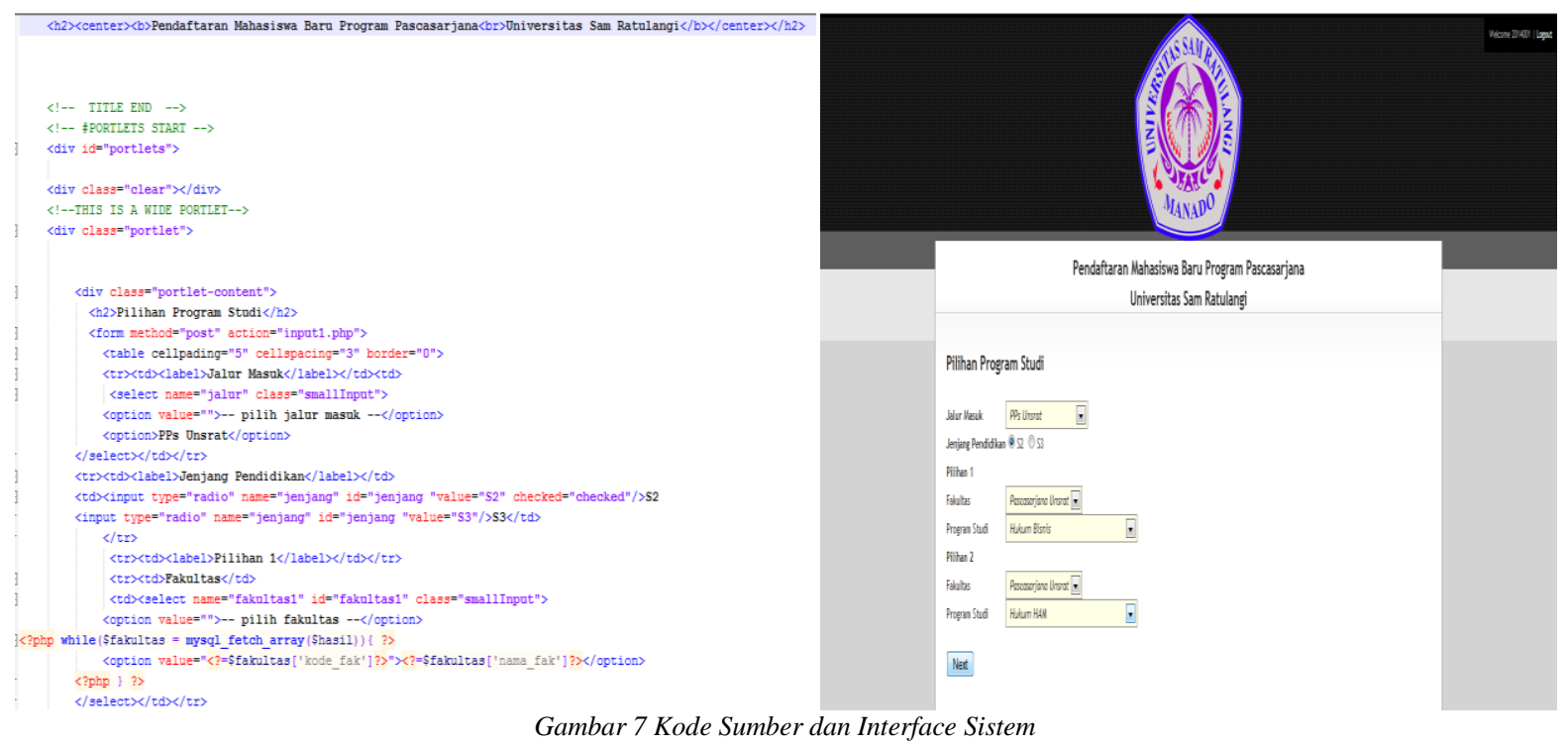

\subsection{Evaluasi}

Tahap evaluasi dilakukan dengan menguji coba hasil perancangan sistem yang telah dibangun pada tahap penerapan metode. Tahap uji coba yang dilakukan yaitu uji coba sistem berdasarkan use case diagram, uji coba tipe-tipe data dalam sistem dengan melakukan proses input data menggunakan data yang sebenarnya, uji spesifikasi minimum hardware dan software yang dapat menjalankan sistem ini, serta offline testing sistem kepada user. Hasil dari tahap ini diketahui bahwa sistem yang dibangun sudah sesuai dengan use case diagram yang dirancang, misalnya untuk use case Entry_Data dibuktikan dengan adanya formulir pendaftaran pada sistem yang dibangun. Selain itu diperoleh hasil berupa tipe data dan jenis data yang dapat dimasukkan ke dalam sistem serta spesifikasi minimum hardware dan software yang dapat menjalankan sistem. Dari evaluasi terhadap hasil offline testing sistem yang dilakukan, diperoleh kesimpulan bahwa sistem yang dibangun sudah baik dan membantu program Pascasarjana Unsrat dalam melakukan proses pendaftaran. Selain itu diperoleh feedback dari user agar sistem segera diimplementasikan.

\section{PENUTUP}

\subsection{Kesimpulan}

Beberapa kesimpulan yang dapat diambil antara lain:

1) Konsep rekayasa perangkat lunak serta analisa dan perancangan sistem dapat menyelesaikan masalah pendaftaran mahasiswa baru di Program Pascasarjana Unsrat.

2) Sistem informasi berbasis web dapat dikembangkan dengan menggunakan kombinasi metode pengembangan perangkat lunak RAD dan WebE.

3) Hasil dari proses perancangan sistem yang dilakukan menghasilkan sebuah Sistem Informasi Admisi yang sudah siap digunakan di Program Pascasarjana Unsrat.

\subsection{Saran}

Untuk penelitian lebih lanjut, disarankan untuk membuat versi mobile-based apllication dari Sistem Informasi Admisi ini.

\section{DAFTAR RUJUKAN}

[1] Sutabri. (2004), Analisa Sistem Informasi, Yogyakarta: Andi Offset.

[2] Karouw. (2012), Analysis and Design Web Portal Amazing North Sulawesi using AUP Methodology, Universitas Sam Ratulangi Manado.

[3] Janner. (2009), Rekayasa Web, Medan: Penerbit Andi.

[4] Kendall. (2008), Analisis dan Perancangan Sistem, Jakarta.

[5] Kendal and Kendall. (2007), System Analysis and Design $7^{\text {th }} e d$, Pearson Prentice Hall.

[6] Pressman. (2005), Software Engineering, A Practitioner's Approach, Singapura: McGrawHill.

[7] Schach. (2008), Object Oriented Software Engineering 8th Ed, McGrawHill.

[8] Boch, Grady. (1999), Unified Modeling Language, OMG.

[9] Romi. (2014), Research Metodology 5. Struktur Penulisan Tesis, Jakarta. 